\title{
How Preservice Teachers' Study Abroad Experiences Lead to Changes in Their Perceptions of English Language Learners
}

\author{
Adriana L. Medina \\ The University of North Carolina at Charlotte \\ Jennifer I. Hathaway \\ The University of North Carolina at Charlotte \\ Paola Pilonieta \\ The University of North Carolina at Charlotte
}

\section{Introduction}

Teacher attitudes toward English language learners (ELLs) can affect what these students will learn. It has been noted that teachers with personal multicultural experiences are likelier to have a more positive attitude towards teaching ELLs (Youngs and Youngs, 2001). Thus, preparing future teachers is vital. This cannot be solely accomplished vicariously through textbooks or only from an intellectual perspective (Cushner, 2007). Instead, experiences with others are needed.

There is value to the method of teaching and learning via lived experiences, as such international experiences are often considered an "essential part of students' preparation for their future" (Martinsen, 2011, p. 121). Many teacher education programs include opportunities for preservice teachers (PSTs) to study abroad. Much of the literature regarding study abroad focuses on linguistic gains and cultural understanding (Martinsen, 2011) as well as the impact on cognitive and affective domains (Cushner, 2007). There is also support for the fact that study abroad experiences can contribute to the preparation of a culturally sensitive teaching force that is knowledgeable about, at ease with, empathic toward, and understanding of culturally and linguistically diverse students (Cushner, 2007; Malewski and Phillion, 2009; Phillion, Malewski, Sharma, and Wang, 2009; Polat, 2010; Willard-Holt, 2001). Yet, studies fail to take into account PSTs' experiences as "others" before studying abroad. This is particularly problematic because since students self-select to study abroad it might seem likely that they have an interest in learning about others and thus would be more predisposed to having positive attitudes towards and experiences with diverse people (Salisbury, Umbach, Paulsen, and Pascarella, 2009). The purpose of this study was three-fold: 1) to examine PSTs' perceptions of "others" before traveling abroad, 2) to compare them to PSTs' perceptions of "others" upon their return, and 3) to attribute shifts in perceptions while abroad to specific experiences PSTs identified as helping them change their perceptions.

\section{Review of the Literature}

There are many reasons teachers need to be prepared to meet the needs of culturally and linguistically diverse learners. First is the fact that many PSTs fail to see extant cultural, ethnic, or racial differences between themselves and their students (Walters, Garii, and Walters, 2009). This results in teachers and school cultures that are not inclusive of culturally and linguistically diverse students and in teachers who fail to meet the needs of their diverse students. 
Second, ELLs are the fastest growing segment of the student population (Alliance for Excellent Education [AEE], 2007). In the past decade, the United States ELL population has grown 18 percent; yet, in the "high-ELL-growth" state where this study took place, the ELL population growth has been 135\% (Horsford and Sampson, 2013, p. 47). However, only 5\% of traditionally prepared teachers and 6\% of alternative route certified teachers are English as a Second Language (ESL) teachers (Feistritzer, 2011). Additionally, 84\% of the teacher workforce is White and female (Feistritzer, 2011), speaks only English and has little or no exposure to children from diverse cultural backgrounds (Sleeter, 2008). Yet, in many U. S. schools, on average, White students make up only $52 \%$ of the school population (National Center for Education Statistics [NCES], 2012) and 21\% of the students speak a language other than English at home (NCES, 2012).

Finally, compounded by the low numbers of ESL teachers, the disparity between teacher preparation and the needs of ELLs impacts achievement. On the 2011 reading portion of the National Assessment of Educational Progress (NAEP), 69\% of ELLs scored below the basic range with only $7 \%$ scoring at or above the proficient range (NCES, 2011). In contrast, 44\% of White students scored at or above the proficient range with only $22 \%$ scoring below the basic range (NCES, 2011). Both inservice and preservice teachers need to be well prepared to teach ELLs. Novice teachers have been known to predetermine expectations for behavior and academic success based on race (Galman, Pica-Smith, and Rosenberger, 2010). Mainstream teachers often report feeling unprepared to teach students who are culturally and linguistically diverse (Polat, 2010; Pray and Marx, 2010). Therefore, preparing PSTs to work with diverse student populations continues to be a focus in teacher education (Phillion et al., 2009).

To address this focus, teacher education programs infuse multiculturalism throughout the curriculum, offer stand-alone classes, require specific field experiences with diverse students, or incorporate study abroad programs. Youngs and Youngs (2001) identified traveling abroad and exposure to ELLs as factors that tended to positively influence PSTs' attitudes towards ELLs, and other research concurs (Polat, 2010; Rodriguez, 2011). Several researchers (see Malewski and Phillion, 2009; Phillion et al., 2009; Polat, 2010) posit that PSTs who participate in study abroad programs develop greater empathy for diverse students and ELLs. Empathy is one of the most important dispositions a teacher needs to educate culturally and linguistically diverse students (Gay, 2000; McAllister and Irvine, 2002). Pray and Marx (2010) found that PSTs returned from study abroad experiences with more empathy towards ELLs, more passion for teaching, and a greater sense of competence in teaching ELLs. Nero (2009) asserted that the empathy gained from studying abroad helps monolingual teachers understand the language learning process. Therefore, study abroad programs have the potential to positively contribute to PST' perceptions of and interactions with ELLs.

The study abroad opportunities in teacher preparation programs vary in length, destination, purpose, and faculty involvement. Each of these components purportedly impacts the level of significance of the study abroad experience; however, even a brief period abroad influences the perspectives of PSTs (Willard-Holt, 2001). Phillion, Malewski, Sharma, and Wang (2009) found that a three-week field experience in Honduras and multicultural coursework had the potential to provide PSTs with the multicultural and global knowledge and awareness needed to bridge the gap between themselves and the diverse students they would teach.

Beyond bridging the gap, there is also a need for PSTs to make the connection between their experiences and the experiences of the diverse students in their future classroom. There is little research examining the link between PSTs' experience as "other" before studying abroad and how that influences understanding of experiences while studying abroad or how that understanding influences perceptions of culturally and linguistically diverse others PSTs will teach in the future. There is one study by Willard-Holt (2001) that 
examined a one-week cross-cultural teaching experience to Mexico. Initially 27 PSTs participated. Data on previous travel experience and interactions with "others" were collected before the trip and then participants were allowed to amend their responses after they returned. Four months later, the PSTs were asked to assess the impact of their experience. Participants reported experiencing personal and professional changes due to the experience. They noted that their preconceptions were "shattered and the experience of being in the minority were powerful impacts of the trip" (p. 515). Willard-Holt (2001) concluded that based on the impact of the experience, the PSTs would be less likely to judge students. The PSTs self-reported that they would have more "patience and empathy and [would] expend more efforts in finding other ways to convey concepts to children who seem not to understand" (p. 515). Willard-Holt noted that based on the study, future research would include "more extensive preparation to maximize the potential benefits of the trip....[and] include examination of the preservice teachers' preconceptions" (p. 515). Additionally, WillardHolt would add a "more in-depth debriefing following the trip to reinforce positive changes ... to explore how the experience might affect their teaching, and to allay any negative impacts" (p. 515). While in that study pre/post data were collected, the study did not link changes in perceptions with participants' preconceptions in order to capture the extent of change. Also, the study indicated that research is needed to identify experiences that tie-in to teaching.

Thus, this study sought to 1) examine PSTs' perceptions of "others" before traveling abroad, 2) compare them to PSTs' perceptions of "others" upon their return, and 3) attribute shifts in perceptions while abroad to specific experiences PSTs identified as helping them change their perceptions.

\section{Theoretical Framework}

Teachers' professional learning is a complex process which has recently been conceptualized as cycles of learning where old beliefs and practices are re-analyzed as a result of gained understanding and new practices. These new understandings in turn lead to re-examination of what was previously known about teaching (Opfer and Pedder, 2011). Mezirow's Transformation Theory (1994) provides a framework that can be used to understand teachers' professional learning.

Mezirow (1994) uses the term perspective transformation to describe adult learning. Mezirow sees learning as a social process in which the meaning of a person's experiences are re-analyzed and re-interpreted and can be used to guide actions and make decisions, irrelevant of whether or not there is an immediate change in behavior. Thus, learning is the result of changes in a person's frames of reference, or the assumptions through which one's experiences are filtered (Mezirow, 1997). These frames of reference affect the way people interpret the world, even when people are not consciously aware of them (Mezirow, 2000).

Critical reflection, whether explicit or implicit, also plays an important role in Mezirow's theory. When a person is faced with information or an experience that does not align with their frames of reference, a sense of disequilibrium occurs. A person is then likely to reject the information or experience that contradicts their frames of reference in order to regain a sense of equilibrium (Mezirow, 1994). However, if critical reflection is employed during that state of disequilibrium, learning can ensue (Mezirow, 1998).

Mezirow (2000) argues that learning, or transformation, occurs through ten phases (see Mezirow, 1991). Once a transformation has commenced, a person does not return to older perspectives. However, movement through the phases does not necessarily occur in a fixed order (Mezirow, 2000). Indeed, Taylor (2000) describes this process as "recursive, evolving, and spiraling" (p. 290) as phases may be repeated several times.

The first phase of transformation is the disorienting dilemma, or an experience a person confronts that 
leads to disequilibrium (Mezirow, 2000). The disorienting dilemma can either be one shocking event or a series of smaller innocuous events (Taylor, 2000). Mezirow (1991) explains that one type of experience that may serve as a disorienting dilemma is when a person attempts to understand the customs of a different culture, even when those customs contradict one's own perspectives.

Taylor (1994) applied Mezirow's Transformation Theory to people living abroad who were developing intercultural competency. In Taylor's study (1994) the disorienting dilemma was akin to culture shock. Additionally, he found that disorienting dilemmas could occur abroad while participating in tasks that would be considered routine at home. Taylor (2000) also argues that emotions play an important role in Transformation Theory in contrast to Mezirow himself who often overlooks them. Taylor (1994) explains that disorienting dilemmas often result in strong emotions like frustration, fear, or loneliness. Though these emotions may make a person uncomfortable, they are often the catalysts for learning.

Another method of learning is through lived experience. Experience plays an important role in the learning process. Lived experience or experiential learning is not a new concept in education; hands-on experiences, or experiencing by doing, are a common practice in education. Studying lived experiences is also not new (Quinn, Morton, and Brindley, 2011). The experiences a person lives through are personal; thus, the interpretation of a lived experience is unique to the individual (van Manen, 1990). While experiential learning allows for an experience to be interconnected with cognition (Cushner, 2007), a lived experience gains " 'quality'... in retrospect" when the experience is looked back upon and meaning is assigned (van Manen, 1990, p. 36). Humans have many forms of expressing their experience of the world, one of which is "through language" (van Manen, 1990, p. 14).

The PSTs in this study made sense of and gave meaning to their experiences through written reflections before, during, and after the study abroad experience. Their reflections formed the basis of the body of data along with pre- and post-questionnaires and group interviews. Mezeirow's Transformation Theory was used as a lens to understand the changes in perspectives seen in the participants of this study.

\section{Methods}

\section{Research Questions}

Two research questions guided this study: 1) What types of experiences did the PSTs identify as making them feel like an outsider before and after studying abroad? 2) What changes in perceptions resulted from the experiences abroad?

\section{Setting}

This study originated at a large urban university in the southeastern region of the United States. The study abroad experience, which is an optional component of the elementary education program, is part of a long-standing relationship with a university in the Bavaria region of Germany. The PSTs began and ended the semester in the United States, but spent eight weeks in Germany, all the while completing methods coursework. In addition to this coursework, the American PSTs had a one-week experience with German PSTs focusing on pedagogy. The PSTs also had opportunities to visit German schools and travel throughout Europe.

\section{Participants}

During the fall of 2011, 16 PSTs participated in the study abroad experience. All of the participants were enrolled in initial licensure programs in elementary education (see Table 1) and completed at least 12 credit 
hours of methods coursework. The PSTs were accompanied by two university faculty members, a White male associate professor with extensive experience with the German culture, and a Hispanic female assistant professor (the third author). The faculty members taught methods courses in literacy and math to the PSTs.

Table 1. Participant Demographics

\begin{tabular}{|c|c|c|c|c|}
\hline Gender & Age & Educational Level & Ethnicity & $\begin{array}{c}\text { Number of Languages Fluently } \\
\text { Spoken }\end{array}$ \\
\hline Female & 20 & Undergraduate (Junior) & White & 2 \\
\hline Female & 20 & Undergraduate (Junior) & White & 1 \\
\hline Female & 20 & Undergraduate (Junior) & White & 2 \\
\hline Female & 21 & Undergraduate (Senior) & White & 1 \\
\hline Female & 21 & Undergraduate (Senior) & White & 1 \\
\hline Female & 21 & Undergraduate (Senior) & White & 1 \\
\hline Female & 21 & Undergraduate (Senior) & White & 1 \\
\hline Female & 22 & Undergraduate (Senior) & White & 1 \\
\hline Female & 22 & Undergraduate (Senior) & White & 1 \\
\hline Female & 22 & Undergraduate (Senior) & White & 1 \\
\hline Female & 22 & Undergraduate (Senior) & White & 1 \\
\hline Male & 22 & Undergraduate (Junior) & White & 1 \\
\hline Female & 25 & Undergraduate (Senior) & Other & 2 \\
\hline Female & 26 & Graduate & White & 1 \\
\hline Female & 29 & Graduate & White & 1 \\
\hline Male & 39 & Undergraduate (Junior) & White & 1 \\
\hline
\end{tabular}

\section{Data Sources}

Three primary sources of data were collected over a four month period: written reflections, questionnaires, and group interviews. Data were collected before, during, and after the study abroad experience.

Reflections. Reflection, a contemplative, attentive consideration of one's experiences and actions (Ross, 1989), has often been used to gather information in research examining the impact of study abroad programs (e.g., McGaha and Linder, 2012; Pence and Macgillivray, 2008). Throughout the study, the PSTs were asked 
to complete written reflections designed to prompt their thinking about experiences related to language barriers, the cultural differences they experienced, and the connections they made between these and the potential experiences of ELL students in their future classrooms. The specific prompts assigned for each reflection can be seen in Figure 1.

Questionnaires. A 37-item questionnaire designed to capture the PSTs' understandings of and knowledge about teaching ELLs was administered before the study abroad experience began and again once the participants returned to the United States. This questionnaire was a modified version of a survey piloted by the third author in a study addressing in-service teachers' experiences with ELLs. The questionnaire had four sections. The first seven items in Section 1 elicited demographic information from the PSTs including their age, gender and ethnic and linguistic backgrounds. Sections 2 through 4 used a one to five scale (from strongly disagree to strongly agree) and asked the respondents to indicate their agreement with statements. Section 2 contained three items designed to capture the PSTs' interest in diversity. For example, the PSTs were asked to rate their agreement with the statement, "I often socialize with people from different ethnic groups other than my own." Section 3, containing ten items, examined the PSTs' knowledge of strategies to teach ELLs (e.g., "I feel confident in my knowledge of research-based strategies to teach the English language to ELLs."). The final section of the questionnaire contained 17 items and addressed knowledge of second language acquisition. For example, the PSTs were asked to rate their agreement with statements such as, "It is appropriate for ELLs to speak their first language in schools."

Group interviews. Semi-structured group interviews were conducted before and after the study abroad experience. These interviews, which were transcribed, were designed to examine the PSTs' attitudes about studying abroad using a Photolanguage approach. This approach uses black and white photographs to elicit responses and has been found to stimulate deeper feedback than traditional interviewing methods (Bessell, Deese, and Medina, 2007).

In the first group interview, the PSTs were asked to select pictures that described how they felt about spending two months in a foreign country and how they felt about teaching ELLs in their own classroom. They selected photographs from the Photolanguage Australia Human Values Sets A and B (Cooney and Burton, 1986) and then shared their chosen photos and the reasons behind their choices. The PSTs were also asked to talk about an experience that made them feel like an outsider.

The final group interview was conducted after the PSTs returned to the United States. A Photolanguage approach was once again used as the participants were asked to find pictures describing their study abroad experience and also how they felt about teaching ELLs in their own classroom. Follow up questions addressing experiences where they felt like outsiders and anticipated ways the trip might affect their plans for teaching ELLs were also posed. 
Figure 1. Reflection prompts

\begin{tabular}{|c|c|}
\hline \multicolumn{2}{|r|}{ Reflection Prompts } \\
\hline $\begin{array}{l}\text { completed before } \\
\text { studying abroad }\end{array}$ & $\begin{array}{l}\text { Reflection } 1 \\
\text { Describe an experience where you felt like an outsider. How did it make you feel? } \\
\text { How might this experience affect your classroom practice? } \\
\text { Reflection } 2 \\
\text { Think about your future classroom and your ELL students. What kind of outsider } \\
\text { experiences might they have in your class? How might they feel? What could you do } \\
\text { to help? }\end{array}$ \\
\hline $\begin{array}{l}\text { completed while studying } \\
\text { abroad }\end{array}$ & $\begin{array}{l}\text { Reflections } 3-6 \\
\text { Describe an experience where you felt like an outsider. How did it make you feel? } \\
\text { How might this experience affect your classroom practice? }\end{array}$ \\
\hline $\begin{array}{l}\text { completed after studying } \\
\text { abroad }\end{array}$ & $\begin{array}{l}\text { Reflection } 7 \\
\text { Think about any experience you had while in Germany that made you feel like an } \\
\text { outsider. How does this experience affect how you feel about people in the United } \\
\text { States who are outsiders? } \\
\text { Reflection } 8 \\
\text { Think about your experience in Germany. What did you learn that you think will } \\
\text { make you a better teacher of ELLs in your future classroom? What ideas do you plan } \\
\text { to implement in your classroom? }\end{array}$ \\
\hline
\end{tabular}

\section{Data Analysis}

Findings presented in this paper are drawn primarily from the PSTs' written reflections and their questionnaire responses. Participants' responses in the group interviews were used to triangulate the data. Quantitative data analysis, specifically descriptive statistics, was used to analyze the PSTs' responses to the questionnaire. Otherwise, data analysis was ongoing throughout the study using a constant comparison method (Strauss and Corbin, 1998). HyperRESEARCH (ResearchWare, 2007), a qualitative data analysis software program, was used to support the analysis as it moved through the stages of open and axial coding. To ensure reliability within the analysis, all three researchers analyzed the first two reflections together. To maintain consistency in the analysis for each subsequent reflection, the researchers worked in pairs, rotating to ensure that each reflection was coded by at least one researcher who had participated in the analysis of the previous reflection. During initial coding, important terms were operationally defined (See Figure 2).

During open coding, more than 50 initial codes emerged with data units varying in size from short phrases to several sentences. When appropriate, data segments representative of more than one theme were assigned multiple codes. At the conclusion of data collection, axial coding was conducted. In the end, seven categories emerged. Figure 3 shows those relevant to the research questions reported on in this study. These categories contained numerous themes within them and were developed from patterns emerging in the data. For example, since the PSTs were asked within their reflections to discuss experiences that made them feel like outsiders, codes capturing the elements they felt contributed to their marginalization led to the creation of the "distancing elements" category. Finally, data collected before the study abroad experience were separated from data collected during and after the PSTs' time abroad within pertinent categories. 
Figure 2. Important terms operationally defined.

\begin{tabular}{|c|c|}
\hline \multicolumn{2}{|r|}{ Definition of Terms } \\
\hline Distancing Element & $\begin{array}{l}\text { An element, situation, or event that puts distance between an individual and } \\
\text { the majority culture and thus prompts feelings of outsiderness or otherness. } \\
\text { This term is similar to Mezirow's (1994) disorienting dilemma that leads to } \\
\text { disequilibrium and initiates the first phase of transformation and similar to } \\
\text { Taylor's (1994) term of dissonance. Informally, this can be referred to as } \\
\text { culture shock. }\end{array}$ \\
\hline Outsider, Other, or Otherness & $\begin{array}{l}\text { An individual that does not belong to a particular group; a cultural outsider; } \\
\text { the state of being an "other." }\end{array}$ \\
\hline Feelings of Outsiderness & $\begin{array}{l}\text { Feeling that one does not know what other people know and thus one feels } \\
\text { like an outsider. }\end{array}$ \\
\hline
\end{tabular}

Multiple steps were taken to ensure the trustworthiness of this work (Erlandson, Harris, Skipper, and Allen, 1993). Using a triangulation of sources and researchers safeguarded the credibility, confirmability, and dependability of the reported findings. Additionally, the researchers maintained a detailed accounting of the research methodology and provided thick descriptions of the PSTs' thoughts and beliefs when reporting the findings within this paper.

\section{Findings}

This section presents findings of PST' experiences as outsiders before and while studying abroad and their perceptual changes resulting from studying abroad. Where applicable, findings are supported by direct quotes from the PSTs' reflections. A reflection number is given to indicate that the quotations came from different reflections and were representative of the entire sample. It should be noted that the purpose was not to analyze each PST's individual development, but rather to understand the common experiences of the participants.

\section{PSTs' Experiences as Outsiders before Studying Abroad}

In their first reflection that was written before leaving for Germany, the PSTs were asked to describe an experience where they felt like an outsider. They also discussed these experiences during the first group interview. These experiences were examined to determine the underlying element that created a feeling of distance from the majority. These elements were ultimately coded as distancing elements. In examining the PSTs' early experiences with outsiderness, a variety of distancing elements were categorized as not fitting in, cultural differences, and gender. 
Figure 3. Relevant coding categories and themes.

\begin{tabular}{|c|c|c|}
\hline Category & Theme & Description \\
\hline \multirow{3}{*}{$\begin{array}{l}\text { distancing } \\
\text { elements }\end{array}$} & culture & $\begin{array}{l}\text { when local customs, ethnic/racial differences, unfamiliar foods, or written/oral } \\
\text { language lead to feelings of outsiderness }\end{array}$ \\
\hline & gender & when gender leads to feelings of outsiderness \\
\hline & not fitting in & $\begin{array}{l}\text { when being new to a group or not fitting into a group lead to feelings of } \\
\text { outsiderness }\end{array}$ \\
\hline \multirow{7}{*}{$\begin{array}{l}\text { changing } \\
\text { perceptions }\end{array}$} & English only & ideas about the role of a student's native language in the classroom \\
\hline & global awareness & valuing multiple languages in a society; having a pluralistic world view \\
\hline & $\begin{array}{l}\text { judgments about } \\
\text { others }\end{array}$ & $\begin{array}{l}\text { judgments based on others' cultures or judgments about America's } \\
\text { monolingualism or treatment of ELLs }\end{array}$ \\
\hline & lessons learned & $\begin{array}{l}\text { lessons that bring about personal growth or lessons learned about other } \\
\text { cultures or language use in schools }\end{array}$ \\
\hline & $\begin{array}{l}\text { perspectives on } \\
\text { diversity }\end{array}$ & $\begin{array}{l}\text { thoughts on diversity ranging from a colorblind perspective to an open- } \\
\text { mindedness towards diverse cultures }\end{array}$ \\
\hline & self judgment & expressions of regret or shame over their own behavior \\
\hline & relating to others & $\begin{array}{l}\text { personal experiences give a taste of otherness, allowing them to relate to } \\
\text { ELLs }\end{array}$ \\
\hline \multirow{2}{*}{$\begin{array}{l}\text { plans to } \\
\text { support ELLs }\end{array}$} & dispositions & $\begin{array}{l}\text { plans for supporting ELLs in the classroom by demonstrating positive } \\
\text { attitudes, values, and beliefs about ELLs }\end{array}$ \\
\hline & accommodations & plans for supporting ELLs in the classroom by implementing specific actions \\
\hline
\end{tabular}

Not fitting in. Seven of the 16 PSTs' reflections focused on experiences in which they felt they did not fit in with their peers. One of the PSTs wrote about her feelings of discomfort as she participated in a weeklong mission trip with a youth group that she did not know before the trip began. Another PST described her struggles to fit in socially with her middle school peers. She described, "I was never part of the 'in' crowd in school.... I was the outsider in a school of kids who thought they were cooler than me" (Reflection1). However, five of the seven PSTs who identified this distancing element wrote about feeling like an outsider after moving to a new place, either as a child or an adult. For example, one PST wrote:

I was the new kid in town. Everyone in my classes grew up with each other and already had their friends. Middle school is already an awkward stage in life and moving to a new town right before that year in school did not make things easier (Reflection 1).

Sometimes the PSTs' struggles to fit in were compounded by the cultural differences the students faced as they relocated which were noted as secondary distancing elements. For example, one PST who moved from a northern state to the southeastern region of the country explained:

I was a minority in terms of where I was from, how I talked, what I was used to, what I had 
experienced, how I thought and acted, and what I believed. Not all of these were polar opposites from northerner to southerner, but there were and still are some notable differences....Accents and the differences in language use still make me feel like an outsider here today....I also really felt and still feel like an outsider when it comes to religion. Many people here have their religion as one of the top priorities in their life. I was not raised that way, nor were many people from where I grew up. I often feel uncomfortable with how prominent religion is here (Reflection 1).

Overall, experiences that fell within the "not fitting in" theme left the PSTs feeling lonely, nervous, overwhelmed, and unwanted or ignored. At times they also felt judged when others made fun of them for being different.

Cultural differences. At times, cultural differences such as customs and language were noted as the primary reason for the PSTs' feelings of outsiderness. Two PSTs identified these types of differences as their primary distancing element. One wrote about his experiences in a Cambodian church as a teenager as "culture shock" (Reflection 1). He particularly struggled with the foods the Cambodians enjoyed. The other PST identified her experiences in another country as a distancing element. Specifically, her lack of understanding of the language left her feeling like an outsider. She explained: "When I first met [my boyfriend's] family in Mexico I felt very uncomfortable because I was unable to speak Spanish. . . . When his family was talking I felt very left out because I did not understand what they were saying" (Reflection 1).

The more prevalent cultural difference that led to feelings of outsiderness for the PSTs was a difference in race. Specifically, six of the PSTs, who were all White, wrote about experiences with African Americans that led them to feel like outsiders. In each instance, the PSTs described situations where they found themselves to be one of the only White people in a gathering of African Americans. Two of these gatherings were social in nature: a party and a church service. However, the others all took place in educational settings. One PST described her experiences as a child in a predominantly African American elementary school while the others discussed experiences from college.

Overall, when race was the distancing element, most PSTs indicated these encounters left them with negative memories. They felt uncertain, uncomfortable, and exposed as a result of their outsiderness. For example, one PST wrote that her experiences as the only White student in a psychology course left her feeling "vulnerable and uncomfortable. I never felt like I could express my opinions or participate in the discussions because my classmates looked down upon me because I was not like them" (Reflection 1). However, a few PSTs did describe positive outcomes from these experiences with outsiderness. One explained that because of her experience in an African American Women's History course: "I am more open minded to those different from me and I am not as naïve. . . This was a good experience for me because it taught me...how to respond to a situation that I did not know much about" (Reflection 1).

Gender. One PST identified gender as a distancing element. In middle school, she was the first girl to ever be on her school's baseball team. Though she was excited to be part of the team, her male teammates did not welcome her. She cut her hair and wore a cap to try to blend in with the boys (Group Interview 1). But her teammates still teased her and left her feeling "miserable, upset, and frustrated the first few weeks because [she] felt like no one wanted [her] to be a part of their team.... Though [she] didn't quit, [she] wanted to every day after [her] feelings were hurt" (Reflection 1).

\section{PSTs' Experiences as Outsiders while Studying Abroad}

Once the PSTs arrived in Germany, they were prompted to reflect on experiences they had that made 
them feel like outsiders. They were also asked to reflect on this topic one last time after they returned to the United States. Primarily all of the distancing elements they faced while abroad dealt with cultural differences, namely language and customs. Two PSTs identified experiences where race was a distancing element.

Language. The most common distancing element the PSTs dealt with while abroad was language. None of the PSTs were fluent in German, and the few who had any knowledge of the language only spoke a few phrases. Because of this, the PSTs often felt like outsiders as they found it difficult to accomplish ordinary tasks such as grocery shopping or arranging for transportation. One PST wrote about an experience of trying to retrieve a package at a German post office. She explained:

[The postal worker] told me that I had to ask for my package in German for her to give it to me. I was very confused at first. I had told her that I couldn't speak German but she insisted that I speak German to get my package. By this time I was very anxious and a little frustrated because all I wanted was to open my package from my mother. I kept telling the women that I couldn't speak German, but she just kept telling me to ask her in German. Eventually, I stumbled my way through a made up sentence and the woman gave me my package (Reflection 6).

Feelings of frustration, discomfort, and intimidation were common results of the PSTs' struggle with the language. At times they also felt embarrassed and as if they stood out like a "sore thumb" (Reflection 4).

Customs. The PSTs also felt like outsiders because of the different customs they encountered while abroad. For example, travel on the railway systems both within Germany and in other major European cities where they traveled felt to them like a challenge. Most of the PSTs had little experience with public transportation systems as they come from a city in the United States that has only recently built a single-line metro railway. The PSTs were often unsure which train to take, had trouble understanding the conductor's messages, and were unaware of the implicit social norms of the trains such as where to sit or how to be considerate of other passengers. The PSTs were aware that their lack of knowledge of the local customs was a disadvantage. One even asserted, "Little children can navigate the trains better than we could" (Reflection 4). The PSTs also found everyday tasks such as ordering food at restaurants or grocery shopping to be a "huge obstacle" (Reflection 3). As was true with language as a distancing element, the PSTs often felt frustrated and embarrassed by their lack of proficiency with local customs.

Race. Though less prevalent during their time abroad, two of the PSTs identified situations in which race served as a distancing element that made them feel like outsiders. One PST received a new roommate from a Middle Eastern country during her time in Germany. While she acknowledged that just having a new roommate was uncomfortable, she also described how when she learned where he was from she felt her "hands getting sweatier with every word he spoke and [her] heart beating faster as [she] thought only to [herself] "What is he like? Could he be like a terrorist?"' (Reflection 5). Another PST had similar feelings of fear and apprehension when she encountered "gypsies" while traveling in Italy (Reflection 5).

\section{Perceptual Changes Resulting from Studying Abroad}

When back in the United States, the PSTs were asked to think about their experiences in Germany and identify what they learned that they thought would make them better teachers of ELLs and what ideas they planned to implement in the classroom. The experiences the PSTs identified as instrumental in changing their perceptions were related to language and culture. The changes they envisioned making when teaching ELLs in the future were based on dispositions of empathy and advocacy. In addition, PSTs showed changes in their understanding and knowledge about teaching ELLs. 


\section{Changes in disposition.}

Empathy. Upon their return, the PSTs were able to empathize with their future ELLs based on specific experiences they had as "others" as they encountered cultural differences. One PST related, "This experience has made me realize just how hard it could be to not know the culture and language of a country and to feel like a complete outsider" (Reflection 3). Another stated:

spending time in Germany and other parts of Europe, I learned how to better put myself into the shoes of ELLs. I have the perspective of being in a completely new and confusing environment, where I had very limited ability to communicate with others around, much like ELLs (Reflection 8).

Overall, PSTs were able to generally extend and relate what they had learned from their personal experiences as "others" to their future classroom and students. Many PSTs "[imagined] that [students] would feel somewhat like [they] did ... awkward, uncomfortable and frustrated” (Reflection 2).

Several PSTs indicated they would exhibit patience with their ELLs because while in Germany people had patience for them. One PST summed it up:

In Germany, the people I encountered had to have patience with me while trying to communicate with me since I did not speak their language. This will be the same for me one day in my classroom when I am trying to teach my ELL students. I will have to remember to be patient with them and to try to help them to find the best ways to communicate with me (Reflection 7).

Often, PSTs in their own words compared their changes in perceptions based on their experiences as "others." One PST said:

Before [emphasis added] I left for my trip I would get so frustrated when I encountered a person who did not speak my language and didn't even attempt to communicate to me in English, now [emphasis added] having been in their shoes I can relate and understand the difficulties they face by being a minority. I have learned to be more accepting of people who are different from me and believe that this change is $100 \%$ due to my experiences and encounters abroad (Reflection 7).

Advocacy. Based on their experiences as "others" before studying abroad, the PSTs were able to extrapolate to their future classroom and students. In order to help their ELLs, the PSTs expressed dispositions of advocacy. One PST stressed that "...NO ONE makes fun of my ELL students; I will make sure that ALL my students understand how to respect each other" (Reflection 2). Another PST stated: "For ELLs, school can be a horribly uncomfortable place. As a future teacher, it is my job to avoid this at all costs. There are many things I can do to help ELLs not experience these things and feel this way" (Reflection 2).

Upon their return from Germany, the PSTs reiterated the idea of advocating for and being supportive of their ELLs in light of needing support themselves while abroad. One PST stated: "I now [emphasis added] know that it is very difficult and frustrating when you don't know another language and it is my duty to prevent this feeling and to help a child overcome this feeling in order to learn" (Reflection 8).

In summary, many of the PSTs' reflections showed that based on their experiences their thoughts and outlook about outsiders had changed and they planned to remember that when they are teaching. One PST stated:

this experience showed me that ... even the way a person writes or talks can be different from what 
one is used to, but just because someone does not do things the same as you, it does not mean it is wrong. In my classroom I need to remember that all of my students are not going to come from the same background that I come from, and they are going to do and say things differently from me. I will have to keep in mind that this is not wrong, but it is just different from how I do things (Reflection 5).

\section{Changes in understanding and knowledge.}

Self-efficacy. Data from the questionnaire indicated that PSTs developed self-efficacy regarding effective instruction for ELLs due to their study abroad experience. Ten questions asked the PSTs to agree or disagree with statements that measured their self-efficacy in effectively teaching ELLs. Every question showed an increase in PSTs' self-efficacy after their study abroad experience. Four questions in particular showed growth higher than 30\% (rating their comfort level in: 1) research-based strategies to teach the English language to ELLs, 2) adapting the curriculum to meet the needs of ELLs, 3) ideas and material to teach students about different cultural holidays and people, 4) strategies to help ELLs learn and adapt to classroom routines) and one in particular showed growth of more than $45 \%$ (selecting resources and materials to effectively teach ELLs). This growth in self-efficacy is purely due to the study abroad experience, as PSTs received no direct instruction regarding how to teach ELLs.

Second language acquisition. Additionally the PSTs felt they had gained knowledge regarding second language acquisition. When asked to agree or disagree with the statement, "I understand the process that children undergo as they learn a second language," 93\% of the PSTs either agreed or strongly agreed with this statement after studying abroad as opposed to $47 \%$ before the trip. The experience of living abroad and being a language minority helped the PSTs relate to ELLs. Though they did not formally learn about second language acquisition theories, the PSTs felt as if they understood the process more after being a language minority themselves.

Language and intelligence. The PSTs also felt they had modified their preconceptions regarding language and intelligence. While most PSTs already had appropriate views regarding language and intelligence before the study abroad experience, afterwards they felt more strongly about these ideas. On the questionnaire, results shifted from $53 \%$ to $80 \%$ of the PSTs strongly disagreeing with the statement, "People who do not speak properly are uneducated" and from $60 \%$ to $93 \%$ strongly disagreeing with the statement, "Children that do not speak English are intellectually slower than English speakers."

Unexpected findings. PSTs' newfound understanding of attitudes in the United States unexpectedly emerged and were often found intermingled with changes in perceptions related to intercultural awareness and global mindedness. There were instances in some PSTs' reflections where they were questioning their own culture after their exposure to a different cultural context. One PST stated:

Usually I thought of minority groups here [in US] as almost ignorant because they hadn't made enough effort to be a part of the American society. It's a lot harder to fit into a society than Americans think it is. We want people to adjust to our ways as quickly as possible, and it just doesn't work that way. ... It is very difficult being a minority whether it's for a short or expanded amount of time (Reflection 7). 
Another PST stated:

Before I went to Germany, I felt like people who could not speak English should learn how to speak English since they were in the United States. However, after going to Germany and experiencing how difficult it is to learn another language, I see now why signs, directions, etc. need to be translated into other languages. These translations would give people who do not speak or read English a chance to read the information (Reflection 7).

A third PST summed it up this way:

I used to believe that America was top dog and that anyone who was not an American was somehow beneath us. In Germany, not being the top dog really made me realize that this is not the case at all. . .. I was actually ashamed to be in ... countries and not know the language that was being spoken. I thought that by seeing how other people lived that I would be more proud to be an American, but this is truly not how I felt at all (Reflection 8).

These statements confirm previous research by Malewski and Phillion (2009) indicating that students who study abroad can "develop positive, but more critical, attitudes toward their own country" (Cushner, 2007, p. 29).

The PSTs were surprised to find that others had critical and negative views of the United States. One PST stated:

it really hurts to hear that some Europeans consider Americans to be arrogant due to [not speaking more than one language]. [My roommate] was shocked when I told him I was only required to take two years of a foreign language. I really feel somewhat ashamed of the fact that I can get by in life with only speaking English, and that many Americans do not want to learn other languages at all, or about other cultures for that matter. I wish I were able to communicate in multiple languages and be as culturally aware as many people are! I find it fascinating that many Europeans start to learn English in as early as their first year of school. I think it's such a great thing and wish that we did this in America (Reflection 6).

\section{Limitations}

It could be argued that one limitation to this study is that a study abroad trip to Germany does not create enough disequilibrium for PSTs because Western Europe might be seen as too similiar to the United States. However, even in a similar culture change can be facilitated (McGaha and Linder, 2012). Additionally, according to the Institute of International Education (2013), Germany ranked sixth place as the leading destination for U.S. study abroad experiences with 9,018 students traveling there during the year 2010-2011. Another potential limitation is the self-reporting inherent in reflections. Two strategies were imbedded into the design of the study to address the issues related to self-report. First, PSTs reflected on the same question on multiple occasions. Second, other data sources were utilized for triangulation. Another limitation is the convenience sampling; however, the sample population in this study reflects the population of today's PSTs. Finally, while the method of analysis did not lend itself to identifying changes in individual PSTs, the data and analysis do allow us to conclude that the PSTs' experiences while abroad caused changes in perceptions. 


\section{Discussion and Implications}

The findings of this study point to the fact that regardless of prior experiences with "others," experiences while abroad offer a plethora of opportunities that can shift PSTs' perceptions of "others" and potentially effect how they will teach ELL students in their future classrooms.

Before the study abroad, students had some experiences with culture that allowed them to feel like outsiders. However, all of the PSTs in this study were from the dominant culture. The experiences they had were very temporary in nature, often lasting only a few hours or several days (i.e., attending a Black Sexual Politics talk, eating a Cambodian meal, a weekend vacation in Mexico). Although most decided to place themselves outside of their comfort zone, they were mainly in situations over which they had some control. When students retrospectively discussed how those early experiences made them feel, they often overgeneralized their feelings. Race was the most common distancing element when it came to culture before students left the country. However, while in Germany for two months, students struggled more with language and customs. While these moments made them feel uncomfortable, as Scottham and Barnes (2009) point out, "distressing experiences [can become] sources of inspiration" (p. 266). As a result, it is recommended that teacher educators help PSTs reframe their moments of distress while abroad into a theoretical, pedagogical, or global frame. ELLs will commonly struggle with language in and out of school and with customs both of the majority culture and school culture. There is benefit in guiding PSTs to understand how their experiences can help them anticipate areas of struggle and implement methods of support for ELLs.

The sample population in this study was made up of individuals from rural places with little exposure to diversity. They were not well traveled and entered the study abroad experience with certain biases. They often expressed sentiments of being color-blind in the classroom, much like Walters, Garii, and Walters (2009) suggest. Thus, the fact that after their time abroad some of these PSTs acknowledged differences between themselves and others and expressed empathy and advocacy towards ELLs is evidence of their growth. Their experiences while abroad that triggered discomfort were the experiences that also allowed for awareness. Consider some PSTs' shift in stance regarding America, for example. For this sample population, namely PSTs primarily from the Southern United States who all remember the events of $9 / 11$, to question anything American can be interpreted to be unpatriotic. In this context, a seemingly simple awareness that there are other perspectives about America, that they can hold a critical stance toward America is a big step, albeit at first glance it might appear an insignificant gain. The same can be said about PSTs' feelings of empathy. While the newly formed views seem rather simple and surface level, they indicate a level of awareness and understanding that was not present before the study abroad experience. Awareness and contemplating action based on awareness are often the first steps towards change.

To truly capitalize on the transformational power of study abroad experiences, it is recommended that during professor-led study abroad experiences, knowledgeable educators assist PSTs in identifying their biases before and during the travel abroad experience and in expanding their knowledge and cultural sensitivity based on their experiences (Terrill and Mark, 2000). As Pray and Marx (2010) suggest, prior to the study abroad trip, PSTs should receive instruction regarding what they might experience while abroad. Debriefing class sessions while abroad and upon return are beneficial to make connections to the classroom and clear up any confusing matters so that PSTs do not leave with erroneous information. In addition, PSTs would benefit from guidance in identifying their dispositions and shifting those feelings into actions that meet the needs of ELLs in the classroom.

In conclusion, experiences while studying abroad impact PSTs as individuals and as future classroom teachers as well. Teacher education programs should strive to provide future teachers opportunities to study 
abroad and live the experience of being the "other." A blending of encounters and the use of reflection can allow for PSTs to experience otherness and learn from it (Menard-Warwich and Palmer, 2012). Making sense of those experiences leads to transformation of perceptions. When allowed to safely explore them, PSTs can change their perceptions (Zainuddin and Moore, 2004). As one PST noted:

Before going on this trip and having these experiences, I was guilty of getting annoyed with people I came in contact with who did not speak English, whether at all or as fluently as I thought they should have. Now after these experiences, I know how those people feel. . . because I have been in their shoes (Reflection 7).

And having teachers who have "been in their shoes" will benefit the education of ELLs and all students.

\section{References}

Alliance for Excellent Education (2007). Urgent but overlooked: The literacy crisis among adolescent English language learners. Issue Brief. Retrieved from http://www.all4ed.org/files/UrgentOver.pdf

Bessell, A. G., Deese, W. B., and Medina, A. L. (2007). Photolanguage: How a picture can inspire a thousand words. American Journal of Evaluation, 28(4), 558-569.

Cooney, J., and Burton, K. (1986). Photolanguage Australia. Sydney, Australia: Catholic Education Office.

Cushner, K. (2007). The role of experience in the making of internationally-minded teachers. Teacher Education Quarterly, 34(1), 27-40.

Erlandson, D. A., Harris, E. L., Skipper, B. L., and Allen, S. D. (1993). Doing naturalistic inquiry: A guide to methods. Newbury Park, CA: Sage.

Feistritzer, C. E. (2011). Profile of Teachers in the U.S. 2011.Washington, DC: National Center for Education Information. http://www.ncei.com/Profile_Teachers_US_2011.pdf

Galman, S., Pica-Smith, C., and Rosenberger, C. (2010). Aggressive and tender navigations: Teacher educators confront whiteness in their practices. Journal of Teacher Education, 61(3), 225-236.

Gay, G. (2000). Culturally responsive teaching: theory, research, and practice. New York: Teachers College Press.

Horsford, S. D., and Sampson, C. (2013). High-ELL-growth states: expanding funding equity and opportunity for English Language Learners. Voices in Urban Education, 37, 47-54. Retrieved from Annenberg Institute for School Reform at Brown University website: http://vue.annenberginstitute.org/sites/default/files/issuePDF/VUE37.pdf

Institute of International Education. (2013). "Top 25 Destinations of U.S. Study Abroad Students, 2010/11 2011/12." Open Doors Report on International Educational Exchange. Retrieved from http://www.iie.org/en/Research-and-Publications/Open-Doors/Data/US-Study-Abroad/LeadingDestinations/2010-12

McAllister, G., and Irvine, J. J. (2002). The role of empathy in teaching culturally diverse students; a qualitative study of teachers' beliefs. Journal of Teacher Education, 53(5), 433-443. doi: $10.1177 / 002248702237397$

Malewski, E., and Phillion, J. (2009). International field experiences: The impact of class, gender and race on the perceptions and experiences of preservice teachers. Teaching and Teacher Education, 25, 52-60.

Martinsen, R. (2011). Predicting changes in cultural sensitivity among students of Spanish during short-term study abroad. Hispania, 94(1), 121-141.

McGaha, J., and Linder, S. M. (2012). The impact of studying abroad on male preservice teachers: A phenomenological investigation. Multicultural Perspectives, 14(3), 163-168. 
Menard-Warwick, J., and Palmer, D. (2012). Eight versions of the visit to La Barranca: critical discouse analysis of a study abroad narrative from Mexico. Teacher Education Quarterly, 121-138.

Mezirow, J. (1991). Transformative dimensions of adult learning. San Francisco, CA: Jossey-Bass.

Mezirow, J. (1994). Understanding transformation theory. Adult Education Quarterly, 44(4), 222-232.

Mezirow, J. (1997). Transformative learning: Theory to practice. New Directions for Adult and Continuing Education, 74, 5-12.

Mezirow, J. (1998). On critical reflection. Adult Education Quarterly, 48(3), 185-198.

Mezirow, J. (2000). Learning to think like an adult: Core concepts of transformation theory. In J. Mezirow (Ed.), Learning as transformation: Critical perspectives on a theory in progress (pp. 3-33). San Francisco, CA: Jossey-Bass.

National Center for Education Statistics (NCES). (2011). The nation's report card. Retrieved from http://nationsreportcard.gov/reading_2011/nat_g4.asp?tab_id=tab2\&subtab_id=Tab_3\#chart

National Center for Education Statistics (NCES). (2012). The Condition of Education, 2011.U.S. Department of Education. NCES 2011-045 Retrieved from http://nces.ed.gov/FastFacts/display.asp?id=96

Nero, S. (2009). Inhabiting the other's world: Language and cultural immersion for US-based teachers in the Dominican Republic. Language, Culture, and Curriculum, 22(3), 175-194.

Opfer, V. D., and Pedder, D. (2011). Conceptualizing teacher professional learning. Review of Educational Research, 81(3), 376-407.

Pence, H. M., and Macgillivray, I. K. (2008). The impact of an international field experience on preservice teachers. Teaching and Teacher Education, 24, 14-25.

Phillion, J., Malewski, E., Sharma, S., and Wang, Y. (2009), Reimagining the curriculum: Future teachers and study abroad. Frontiers: The Interdisciplinary Journal of Study Abroad,18, 323-338.

Polat, N. (2010). A comparative analysis of pre- and in-service teacher beliefs about readiness and selfcompetency: Revisiting teacher education for ELLs. System, 38, 228-244.

Pray, L., and Marx, S. (2010). ESL teacher education abroad and at home: A cautionary tale. The Teacher Educator, 45, 216-229.

Quinn, S. M. F., Morton, M. L., and Brindley, L. (2011). A window of opportunity: perspectives of preservice teachers from the United States on the customs and practices of teaching in primary schools in England. Teacher Development, 15(1), 37-52. doi: 10.1080/13664530.2011.555223

ResearchWare, Inc. (1988-2007). HyperRESEARCH (Version 2.8). Randolph, MA.

Rodriguez, E. (2011). What pre-service teachers bring home when they travel aboard: rethinking teaching through a short international immersion experience. Scholar Practitioner Quarterly, 5(3), 289-305.

Ross, D. D. (1989). First steps in developing a reflective approach. Journal of Teacher Education, 40(2), 22-30.

Salisbury, M. H., Umbach, P. D., Paulsen, M. B., and Pascarella, E. T. (2009). Going global: understanding the choice process of the intent to study abroad. Research in Higher Education, 50, 119-143. doi: $10.1007 / \mathrm{s} 11162-008-9111-\mathrm{x}$

Scottham, S., and Barnes, J. (2009). Transformational experiences and deep learning: the impact of an intercultural study visit to India on UK initial teacher education students. Journal of Education for Teaching, 35(3), 257-270. doi: 10.1080/02607470903091294

Sleeter, C. (2008). An invitation to support diverse students through teacher education. Journal of Teacher Education, 59(3), 212-219.

Strauss, A., and Corbin, J. (1998). Basics of qualitative research. Techniques and procedures for developing grounded theory (2nd ed.). Thousand Oaks, CA: Sage.

Taylor, E. W. (1994). Intercultural competency: A transformative learning process. Adult Education Quarterly, 44(3), 154-174.

Taylor, E. W. (2000). Analyzing research on transformative learning theory. In J. Mezirow (Ed.), Learning as 
transformation: Critical perspectives on a theory in progress (pp. 285-328). San Francisco, CA: Jossey-Bass.

Terrill, M. and Mark, D. L. H. (2000). Preservice teachers' expectations for schools with children of color and second-language learners. Journal of Teacher Education, 51(2), 149-155. doi: 10.1177/002248710005100209

van Manen, M. (1990). Researching lived experience: Human science for an action sensitive pedagogy. London: Althouse Press.

Walters, L. M., Garii, B., and Walters, T. (2009). Learning globally, teaching locally: incorporating international exchange and intercultural learning into pre-service teacher training. Intercultural Education, 20(S1-2), S151-158.

Willard-Holt, C. (2001). The impact of a short-term international experience for preservice teachers. Teaching and Teacher Education, 17, 505-517.

Youngs, C. S., and Youngs, G. A. (2001). Predictors of mainstream teachers' attitudes toward ESL students. TESOL Quarterly, 35(1), 97-120.

Zainuddin, H., and Moore, R. A. (2004). Engaging preservice teachers in action: research to enhance awareness of second language learning and teaching. Teacher Education and Practice, 17(3), 311-32 
